\title{
Toward the usable recognition of individual benefits and costs in regulatory analysis and governance
}

\author{
Carl F. Cranor* \\ Department of Philosophy, University of California, Riverside, CA, USA
}

Adam M. Finkel

Penn Program on Regulation, University of Pennsylvania Law School, Philadelphia, PA, USA and School of Public Health, University of Michigan, Ann Arbor, MI, USA

\begin{abstract}
Regulatory agencies in the United States and Europe have well-deserved reputations for fixating on the total benefits and costs of proposed and final regulatory actions, without doing any more than anecdotally mentioning the subpopulations and individuals who may bear disproportionate costs or reap disproportionate benefits. This is especially true on the "cost" side of the cost-benefit ledger, where analysts exert little effort to even inform decisionmakers and the public that the costs of regulations might be distributed either regressively or progressively. Many scholars and advocates have observed that regulation can increase the efficiency of market outcomes, but caution about its untoward (or suboptimal) effects on equity. Here, we argue that without considering distributional information about costs and benefits, regulatory policies in fact can also cause violence to notions of efficiency, for two reasons: (i) society cannot hope to approach Pareto-efficient outcomes without identifying those who must lose so that others can gain more; and (ii) because the harm experienced by involuntary risks and by imposed regulatory costs is likely non-linear in its magnitude (at the individual level), efficiency is, in fact, a strong function of the shape of the distribution of these effects. This article reviews evidence about the distribution of regulatory costs and benefits, describes how agencies fail to incorporate readily available distributional information, and sketches a vision for how they could analyze costs and benefits to promote more efficient regulatory choices and outcomes.
\end{abstract}

Keywords: cost-benefit analysis, efficiency, interindividual variability, utility functions, valuation.

\section{Introduction}

A major goal of public policy for environmental, health, safety, and other risk-reducing interventions is that society should undertake such actions when they do more good than harm. Over time this has gained some degree of rigor through the development and institutional growth of cost-benefit analysis (CBA). Cost-benefit analyses can be "hard," wherein a point estimate for total benefit must exceed a point estimate for total cost, or they could be "soft," wherein the estimates are acknowledged to be uncertain and are used as one of many inputs, or various positions in-between.

Cost-benefit analysis presupposes that when analysts quantitatively estimate the social goods and social harms of a proposed policy, rational discussion can ensue about whether it is prudentially wise as well as whether it is ethical. An accurate, detailed, and useful CBA would seek to estimate all of the benefits as well as all of the costs from pursuing the policy, in order to provide an appropriate characterization of costs and benefits, their ranges, and the degree of certainty with which they can be estimated to guide social decisionmaking. In particular, it would estimate these costs and benefits in a way that would allow each person and business affected by a public policy (a beneficiary of its salutary effects, and/or a payer of its costs) to see the policy through the lens of self-interest, as well as through the lens of citizenship. ${ }^{1}$ It would tee up the question "what does the choice of action (or inaction) mean for me and for people like me (or for my business and businesses like mine)?," in addition to the traditional "what does it mean for society?" question.

Correspondence: Carl F. Cranor, Department of Philosophy, University of California, 900 University Avenue, Riverside, CA, 92521. Email: carl.cranor@ucr.edu

Accepted for publication 15 June 2016. 
We begin from the empirical premise that this forthright and sober assessment from two leading environmental economists is as true today as it was 13 years ago: "Given the pervasiveness and magnitude of environmental regulation, one would think that comprehensive studies of the cost and benefit distribution of these policies would be bountiful. Ironically, the contrary is true" (Pizer \& Kopp 2003, p. 33). Indeed, more recent surveys confirm that despite routinely acknowledging the importance of considering how costs and benefits are distributed, American federal and state regulatory agencies rarely seriously analyze distributional matters, particularly on the "cost" side of CBA (Robinson et al. 2016; Williams \& Broughel 2015). We know of no parallel empirical studies of whether regulators in the European Union (EU) similarly fail to quantify distributional impacts, but various personal communications (see the end of this Introduction) suggest that the observations and recommendations in this article apply equally or more so to EU member countries.

We also begin from an important - and, we believe, often misunderstood - ethical foundation. Obviously, considerations of interindividual distribution can determine whether policy actions (or inactions) are "fair," and hence whether they are morally justified (Rawls 1971). However, even before any arguments about equity come into play, distributions of benefits and costs must be considered. We assert this because not knowing distributions can produce inefficient policies, as well as inequitable ones. There are two reinforcing reasons why equity promotes efficiency rather than the two being decoupled or in a zero-sum relationship. First, few if any regulatory policies yield Pareto-efficient outcomes, wherein no individual in the population is made worse off; instead, nearly all policies are gauged via the weaker Kaldor-Hicks test, wherein the total gains to the "winners" under a policy intervention must exceed the total losses to those made worse off. But such outcomes are only efficient if (and because) the winners could, in theory, compensate the losers without exhausting the sum of their gains, thus converting the intervention into one that truly is Paretoefficient. Although many policymakers and scholars argue that such compensation does not have to occur in practice, ignoring distributional information also makes the compensation impossible in theory, as many winners and losers will not even know that they have won or lost (nor will decisionmakers know whom to compensate). ${ }^{2}$ Consequently, we assert that no outcome can maximize social benefit if the parties who must lose so that others may gain more are not even aware that they are being asked (really, being told) to accept this uncompensated loss of welfare. ${ }^{3}$

Moreover, even in the few cases where benefits and costs are disaggregated, current CBA practice does not, in fact, reliably yield estimates of net benefit, the heart of the efficiency criterion. In general, societal net benefit is the sum of the net benefit experienced by each citizen. But mainstream CBA operates under a fundamental assumption that only holds true in the fortuitous special case when the benefit is a linear function of the risk reduced, and where the economic harm is a linear function of the expenditure. In such a special case, the total benefit is insensitive to its distribution, and one can estimate it by multiplying the average benefit by the number of beneficiaries. But more correctly, total benefit is the integral of each person's risk reduction multiplied by the welfare placed on that reduction. If there are any thresholds or non-linearities in the relationship between risk reduction and welfare, then the "body count" (the expected number of statistical lives saved), or a similar aggregated estimate of environmental improvement, will misestimate the actual benefit as experienced by those affected (see Section 5).

On the cost side, a similar leap of faith governs current practice: total cost only equals the total reduction in welfare when welfare is a linear function of cost - and this shortcut directly contradicts the fundamental economic principle of the diminishing marginal utility of money (Section 3.2). Thus, information on how individual costs and risks are interpreted, and how distributions of cost and benefit correlate with noteworthy features of these interpretations, is required to justify or enhance current CBA practice, not merely to pay homage to the domain of equity and maldistribution per se. For example, a situation where 1000 people face a very high individual risk of $1 / 1000$ is not simply less "fair" than a situation where two million people face a very low risk of $1 /$ million; $^{4}$ the former situation may create more harm than the latter, when harm is seen as experienced by those affected, not simply as an abstraction.

Importantly, the ultimate reason to consider disaggregated benefits and costs is not merely to promote better analysis, but to promote better governance. The two are tightly linked, of course, as quantitative analysis of costs and benefits becomes more "triumphant" as the organizing principle for choosing among regulatory options (Sunstein 2012). But at least three of the core issues in the regulatory governance literature concern not how analysis influences decisions, but how a representative government can or should influence the conduct of analysis. First, the legal/policy literature on how regulatory agencies can function under vague statutory language (or whether the legislature is at fault for actively or passively delegating lawmaking powers to the executive that it should reserve to itself; see Ginsburg \& Menashi 2010) bears on whether agencies should be given more or less discretion over how to analyze and respond to the distributional consequences of their choices. Second, the literature about how the executive oversees his agents in the bureaucracy 
generally concludes that such oversight is "reactive" (and that often the executive learns of a controversial agency decision because it imposes concentrated harms on a vocal interest group); therefore, more formal and routine attention to distribution could allow for more proactive oversight (West 2015). Third, the literature on agency capture (see Section 4.1) raises concerns about a lack of transparency exacerbated by the overaggregation of costs and benefits (if an agency decision favors an interest that has vocally and publicly expressed its concerns, especially during public hearings, the result is often called "responsiveness," rather than capture).

The common theme here is that by failing to quantify distributional impacts more rigorously, agencies leave themselves with only two polar options to deal with disparate impacts that do come to their attention: to express rhetorical concern but make no changes, or to allow them to trump all other concerns. We are trying here to offer a pathway toward giving concentrated costs and concentrated risks their proportionate weight, not zero or infinite weight, and to give de minimis costs and risks their proportionate weight - not rounding down to zero impacts that citizens experience as nonzero, nor treating as nonzero impacts that no one wants to count at all. Giving real effects their appropriate weight is fundamentally a way for decisionmakers to take the reins of analysis and make sure that it empowers them to be the principals, rather than have others pulling the strings. We included the word "usable" in our title to connote our hope that recognition of disparate impacts should be more than rhetorical.

This paper is largely theoretical and exploratory on the kinds and ranges of interindividual benefits (and kinds and ranges of costs) that, in principle, should be taken into account in a more accurate and socially responsive brand of CBA. It likely poses more questions than answers. The article also assumes that CBA will continue to entrench itself as the primary method for regulatory analysis. But by confining this article to how CBA can be improved, we do not mean to close off discussion of governance paradigms that eschew CBA entirely. Alternatives to cost-benefit decisionmaking include the precautionary principle (Fisher 2007), technology options analysis (Ashford 2005), or simply requiring the installation of the "best available technology," rather than looking at risk at all (Wagner 2000). Almost by definition, none of these methods can consider both concentrated risks and concentrated costs: the precautionary principle can only do one or the other (generally it is thought of as leading to policies favored by the political left, but in a well-known example [Stern \& Wiener 2006], extreme precaution was invoked to justify the American invasion of Iraq); technology-based standards start from the premise that if a level of protection cannot currently be achieved, its benefits and costs cannot be discussed at all. So because this is a paper about individual impacts, we assume, and not all will agree, that we should use some kind of risk-cost balancing paradigm. Of course, there are also more expansive and deontological versions of risk-cost balancing. In particular, see Kysar (2010), who calls for a more "moral" regulatory framework. We think our recommendations here are very concordant with his, because he organizes his book around three ways CBA fails morally (narrow vision, inability to confront "deep uncertainty," and unwillingness to do better than maximize overall well-being), and (as the first failure) criticizes CBA for not considering future generations, non-human species, and citizens outside the country where the regulation is written. By focusing our discussion here on maximally affected subpopulations, we are suggesting that they too constitute a category of impacts traditional CBA should make better room for.

The remainder of this paper focuses on four broad issues. First, what guidance does the organic structure of various statutes provide for risk assessors and economists to carry out their tasks with reference to interindividual variability in costs and benefits? Second, what (in very general terms) do risk science and regulatory economics tell us about how broadly and unequally distributed typical risks and costs tend to be? Third, how have risk assessors and economists actually incorporated information or informed assumptions about individual costs and benefits when carrying out their tasks? Fourth, and most importantly, how should CBA be conducted given what is reasonably known about the benefit and cost effects on individuals or representative groups of people?

As scholars of regulatory analysis and policy in the United States (US); one of us being a former federal rule-writer and enforcement official there), we focus Section 2 on the US situation. We have, however, discussed laws and guidance documents in the EU and its member states with several leading European scholars, and they agree that there is certainly no greater attention to distributional matters there than in the US. For example, Professor Jacopo Torriti (University of Reading, United Kingdom [UK]) offered:

I am not aware of any guidelines or indeed individual pieces of analysis which deal with distributional issues adequately in Europe. In a way, difficulties with addressing distributional issues associated with CBA are taken as part of the cons of the tool. 
As we will discuss in Section 5, we conclude that in both the US and the EU, distributional impacts are relegated to secondary considerations ancillary to "efficiency." In the US, Executive Order 12866 (1993) instructs agencies to "maximize net benefits (including potential economic, environmental, public health and safety, and other advantages; distributive impacts; and equity)." However, even assuming that this text means that agencies should consider (as opposed to "maximize") distributive impacts, they are clearly a second-order nicety grafted onto a primary requirement. The EU stance is quite similar: the European Commission's "Better Regulation Guidelines" state that "Impacts should be assessed from the point of view of society as a whole although distributional effects and cumulative burdens on individual parties should also be proportionately assessed and considered" (European Commission 2015a, p. 28). Similarly, the influential 2013 Centre for European Policy Studies report for the Commission states that the tenth and final step in CBA is to "consider distributional and cumulative impacts," and that this step is expressly "optional" (Renda et al. 2013, p. 201). We therefore believe that our analysis here is equally relevant to both US and European regulatory analysis and governance.

\section{Legal considerations governing consideration of interindividual distributions}

\subsection{Those governing risk assessment}

To a large extent, the statutory framework guides how risk assessments should be conducted. Some laws may require that susceptible subpopulations be explicitly considered in the analysis, while others may only require that the total benefits and costs of the policy be compared. Enabling legislation might also prescribe when agencies are forbidden from considering tail risks or costs, although we know of no such examples. We briefly review some statutes and how US agencies have either taken advantage of Congressional silence on an issue in order to inform citizens or have chosen to interpret Congressional silence as an explanation for not exploring individual risks (for an excellent general discussion of the distinctions among legislative requirements, proscriptions, and discretion, see Sunstein 2002, Chapter 8).

Some legislation provides glimpses of the need for health protection for citizens under the tail of risk distributions (Cranor 1997). For instance, the legislative history of the Clean Air Act of 1970 calls attention to the effects on typically more susceptible subpopulations: the elderly, children, and those with pre-existing or special conditions, such as chronic obstructive pulmonary disease, heart disease, or pregnancy (Friedman 1981; Health Assembly of the American Thoracic Society 1996).

The Food Quality Protection Act of 1996 authorizes special studies of children's consumption patterns, requires that the "special susceptibilities of children and infants" be taken into account, requires the publication of a "specific determination regarding... safety for infants and children," and requires that "there is a reasonable certainty that no harm will result to infants and children from aggregate exposure to the pesticide chemical residue" (Food Quality Protection Act 1996; Cranor 2011). ${ }^{5}$

The Occupational Safety and Health Act of 1970 requires that "no employee" should suffer "material impairment of health or functional capacity" even if the employee spent a working lifetime exposed to a toxicant. This formulation, as well as some language in the well-known "Benzene" case (Industrial Union Dept. v. AFL-CIO, 1980) suggests that Congress was primarily concerned about individual risks to employees, not increased consequences ("body counts") to affected groups of employees. While this may not be a universal interpretation of the statutory language, it seems to us the best way to understand it (Finkel 2016). ${ }^{6}$

Some other statutes do not appear to single out susceptible subpopulations for legal protection. For example, the Consumer Product Safety Act (1972, 15 U.S.C. \$2056 at Sec.7) requires safety standards for products that are "reasonably necessary to prevent or reduce an unreasonable risk of injury associated with such product," without mentioning any heightened risks based on exposure or susceptibility.

In the US, in addition to statutes, Executive Order 13045, issued by President Clinton, directs "all federal agencies to (1) identify and assess health and safety risks that may disproportionately affect children, and (2) ensure that agency activities address such risks" (US Environmental Protection Agency [EPA] 2006; Institute of Medicine [IOM] 2006). An earlier Executive Order (Executive Order of the President No. 12898 1994) also requires agencies to develop an environmental justice strategy, which includes identifying and addressing "disproportionately high and adverse human health or environmental effects of the programs, policies, and activities on minority populations and low-income populations" (IOM 2006). 


\subsection{Those governing adverse cost effects on regulated businesses}

Two major laws guide US regulatory agencies' approaches to costs upon small businesses, which overwhelmingly tend to be the category of cost impact that receives special attention. Under the Regulatory Flexibility Act of 1980 (RFA), federal agencies such as the Environmental Protection Agency must consider the economic impacts rules will have on small entities, and further procedural requirements seek to ensure that small entities have a voice when the EPA makes policy determinations in shaping its rules. (US EPA 2016)

The more recent Small Business Regulatory Enforcement Fairness Act of 1996 (SBREFA) amended the RFA and requires:

EPA [and OSHA] to convene a small business advocacy review panel prior to proposing any rule that will have a significant economic impact on a substantial number of small entities. It permits small entities adversely affected by a final rule to challenge the agency's compliance with the RFA's requirements in court.

Thus, small business representatives, unlike other advocates, have at least two significant chances to influence the rule aimed at protecting the public. ${ }^{7}$ Moreover, their intervention is only on the cost side (Shapiro \& Goodwin 2013). They typically do not address benefits to the public health that are the purpose of a rulemaking. These seemingly innocuous procedural features of two laws concerning small businesses create crucial and inherent asymmetries with substantial impacts: ${ }^{8}$ when government regulates, or regulates more strictly, on behalf of tail risks, we know about it (the final rule must disclose the stringency of the rule and the reasons for it). But when it declines to regulate, or regulates less strictly, on behalf of "tail costs" to business, the public may never know. There exists no compendium of "regulations discussed internally and shelved because of business concerns."

\section{Interindividual variability in health risks and regulatory costs}

Our concerns about risk and cost interindividual distributions are founded on empirical data about the real-life breadth and severity of high risk or high cost effects on individuals or subpopulations, the focus of this section. On risks, hundreds of thousands of US workers routinely face excess lifetime risks of 1/500 or greater from toxic-substance exposure (US Occupational Safety and Health Administration [OSHA] 2006), and many studies estimate reasonable upperbound cancer risks to citizens from ambient air pollution in excess of 1/1000 (e.g. Linder et al. 2008). In both cases, the center and left-hand (lower risk) tails of these distributions are likely orders of magnitudes smaller than these high probabilities. On costs, one of our prior studies under this same National Science Foundation grant found that a vehicle-miles-traveled tax in metropolitan Washington DC could impose individual costs for highly-skilled workers more than three times those for lower-skilled workers (Harrington et al. 2014); similarly, many studies have estimated that per-employee costs of environmental regulations on small firms ( $<20$ workers) can be more than four times those of large firms (and over $\$ 20,000$ per employee in the aggregate; e.g. Crain \& Crain, 2010). Here, we provide a brief overview of the factors that tend to broaden these interindividual distributions.

\subsection{Benefits of regulatory policies}

Various biological and other factors can increase an individual's or subpopulation's risk of disease compared to a "typical" rate, according to the National Research Council (NRC 1994). These can be roughly divided into variability in susceptibility and variability in exposure. The references cited in this section generally suggest how much information about the interindividual distribution of risk is already collected, or can readily be inferred, during the regulatoryanalysis process (Hattis \& Barlow 1996; Hattis 1997).

3.1.1. Variability in susceptibility. A person's genetic sequence can increase susceptibility to environmental insults and increase the risk of cancer from irradiation or chemical carcinogenesis by a factor of ten-fold or more (Finkel 1997). For example, up to 80 percent of various human populations are "slow acetylators" who detoxify various drugs and environmental chemicals (notably aromatic amines) far less efficiently than those with the "fast acetylator" phenotype (Vesell 1985).

A person's life-stage can increase susceptibility to disease compared to healthy middle-aged persons (Hattis, Goble, \& Chu 2005). For instance, pubescent women's exposure to ionizing radiation or to dichlorodiphenyltrichloroethane (DDT) can increase the rate of breast cancer later in life by a factor of five to ten times more than similar exposures later 
in life would (NRC 1994; Cranor 2011). The placenta is a limited protective barrier against toxicants when fetuses are in utero (Cranor 2011); thus, they may be exposed during development because of toxicants in the mother's body or affected by fathers' or mothers' exposure before a woman even becomes pregnant (Anthes 2010).

In addition, developing children have fewer defenses because their blood-brain barrier, immune systems, detoxifying enzymes, and livers are less developed than adults. And they can have greater exposure in utero and following birth on a per body weight basis than adults (Cranor 2011; Dietert \& Piepenbrink 2006; Grandjean \& Landrigan 2006; Dietert \& Zelikoff 2010).

While early life development puts people at greater risk from toxic exposure, as humans age they can be vulnerable for somewhat different reasons. Their immune system may not function as well in old age as it did at the height of their health. For another example, Parkinson's disease researchers have found that although early life hits might damage areas of the brain that can later lead to Parkinson's, for a time the remaining cells can compensate for the underproduction of dopamine by damaged cells. However, as the healthy cells age, they are less able to compensate and a person may begin to suffer from Parkinson's (Barlow et al. 2007).

3.1.2. Variability in exposure. Some people may be exposed to (much) greater concentrations of a toxicant than others. For instance, the public is exposed to much higher concentrations of ozone in the Los Angeles Air Basin, compared with rural areas of Wyoming, Colorado, or Hawaii. In other instances, a single chemical may enter people's bodies by multiple routes resulting in "aggregative" effects (Cranor 2011). Other subgroups may experience cumulative exposure - different substances enter the body, but act by a common mechanism (Cranor 2011).

Still other synthetic chemicals may not attach to the same cellular receptors, but affect distinct pathways and act by different mechanisms, and adversely affect the same endpoint. For example, dioxins, polychlorinated biphenyls (PCBs), perchlorate, and brominated flame retardants can all adversely affect thyroid uptake, putting developing fetuses at risk of neurological damage (Woodruff et al. 2008; Cranor 2011). Thus, a more complete risk analysis would anticipate when people had co-exposures in order to try to identify when more than one toxicant would affect a particular subpopulation.

\subsection{Economic costs of regulatory policies}

Just as a more complete and personally relevant assessment of social benefits should be considered in a CBA that assesses risks, in principle, greater disaggregation should also be considered on the cost side of the ledger.

On the face of it, a reasonably complete CBA would, at a minimum, consider how a regulatory policy would impact sole proprietorships, various partnerships (and of what kind), and various corporations (and of what kind). Or, time permitting, a more detailed analysis could consider the impacts on individuals from the effects on such business entities.

Some generic observations can be made merely from the kinds of business entities affected. If a regulatory policy adversely affects the income of a sole proprietorship, it may face something of a double-whammy - decreased income plus decreased ability to pay debts owed to others. Of course, even sole proprietors or simple partnerships can reduce or avoid personal debt burdens by declaring bankruptcy. However, debt holders would then be adversely affected.

In contrast, if a policy adversely affects a corporation, the shareholders may have their shares decrease in value. However, if share values decrease to zero and the corporation has to declare bankruptcy because it cannot cover its debts, the shareholders would not have to pay them off. Of course, any adversely affected debt holders should also be included in a CBA. In principle, analysts should consider how, for example, the elderly and pensioners might be affected as individuals if a regulation adversely affected the corporation whose shares (or bonds) they owned.

Some analogues to adverse health effects could alert analysts considering the cost side. A sole proprietorship, partnership, or corporation could face several different environmental or other regulations of its business activities that had a cumulative impact on economic health. Should analysts not take these into account, even if no single impact would be deemed significant on its own merits? Similarly, should analysts take into account "life-stages" of a sole proprietorship, partnership, or corporation, especially start-up businesses, whose economic condition might be more vulnerable in the early years than it might be later as a mature business?

Such internal choices can ripple to others. If companies merely absorb additional costs, this is likely to reduce their profit margins. This might have minimal or more serious effects on the economic health of the business and its 
shareholders. If they raise prices, depending upon the elasticity of demand for their products, this might or might not reduce the quantity of goods or services they are able to sell, and, hence, the number of employees they can hire and pay wages to (Coglianese et al. 2014). Although in some cases there might well be no net job or economic losses considered across the entire economic system, the central premise of this paper is that analysts should also examine the interindividual distribution of economic gains and losses as part of a more complete analysis.

As is the case with risk information, a general sense of the distribution of regulatory costs, and the nature of the subgroups most severely affected, can often be derived from first principles and from information already collected during regulatory analysis. Estimates of the elasticity of demand for the product(s) whose prices will be affected by regulatory compliance costs largely determine how costs will be allocated between producers and consumers (Fullerton 2011); then, the economic observation that some goods are "inferior" (for which demand decreases as consumer income rises), while others are luxury goods (for which demand increases among the richest consumers), largely determines whether those costs borne by consumers will be allocated progressively or regressively by income. For example, Fullerton and West (2003) explain that although gasoline is generally a necessity (the rich may consume somewhat more of it in absolute terms than the poor, but as income goes up, the fraction of one's income spent on gasoline goes down), this relationship does not hold among the very poorest citizens, who cannot afford to own a car and who, thus, are not as sensitive to rises in gasoline prices as are lower middle-class citizens.

We close this section with a cautionary point. The application of economic analysis to regulatory issues requires consideration of the marginal utility of income, a subject about which economists appear to be torn. On the one hand, theoretical economists regard the diminishing marginal value of money as axiomatic. For instance, Hershleifer's Price Theory (1980, p. 69) asserts:

...diminishing Marginal Utility... was and is widely believed... It corresponds to our common-sense notion that more income makes us happier, but we usually get more of a thrill from our first million than from our tenth.

Thus, while costs are expressed in absolute dollar units, the impact of those costs will manifest itself as a fraction of one's wealth. Thus, the impact of a $\$ 10,000$ cost on a pauper will be quite substantial, while the same dollar cost on a billionaire will likely have little impact.

We are, therefore, concerned that regulatory economists often do not pay attention to the diminishing marginal utility of money in practice. This is a mistake, both from a utilitarian and from a distributive point of view, concealing important information that should be known to regulators and the public. More importantly, because the utility of changes in wealth is non-linear and depends on the wealth of each affected person, the expected total cost of a regulation may differ substantially from the more theoretically correct measure, the expected loss of utility. As a group of US researchers has pointed out:

The welfare implications of positive net benefits would be especially murky if the losers tended to be poorer than the winners. Conventional utility theory, which lies at the basis of welfare economics, usually posits that the marginal utility of income decreases as income increases. In other words, use of the net benefits criterion fails to account for the possibility that income losses to the poor would reduce their satisfaction more than income gains to the rich would improve theirs. If that were true, then positive net benefits on a monetary scale would mask negative net benefits when dollars are expressed in units of utility—even on an aggregate basis ignoring distributional and equity issues ((Harrington et al. 2014, p. 2), emphasis added).

Similar criticism of conventional CBA has been raised in Europe:

...these [neoclassical] economists have absolutely nothing to say about the redistribution of resources: a cent of Euro is worth to rich Bob as much as it is to poor Alice. And this is quite strange, as the available empirical evidence testifies in favor of decreasing marginal returns of income (Renda 2011, p. 122).

\section{How have environmental health agencies incorporated distributional information into their cost- benefit analyses?}

We observe that agencies have a general tendency to estimate adverse health/environmental effects - and market costs for preventing them - with little special concern for the interindividual distribution of risks or costs (about which we 
explain further). We also believe that agencies tend to valuate adverse effects in a simplistic, linear fashion, but with some exceptions that are not even-handed. Of course, on some occasions, particular CBAs may have recognized some adverse effects to some subsets of the population, but they have not generally traced this out as thoroughly as we recommend in the final section of the paper.

\subsection{How do agencies disaggregate adverse health effects in CBA?}

Ideally, agencies would communicate important interindividual differences in risk - both those driven by differences in exposure and those driven by differences in susceptibility (Finkel 2013) - and craft policies responsive to those differences to the extent feasible. Over the past 30 years, agencies have made progress communicating important differences in exposure associated with age, geography, lifestyle, and other factors, and have developed decision tools that allow individuals to estimate the risk they face as a function of their own personal exposure (e.g. nomograms that estimate risks and benefits of fish consumption by amount and variety consumed; US EPA 2011) and to consider "fenceline protection" from fugitive emissions from oil refineries in order to address some environmental justice issues (Earthjustice 2014; Fox 2015). However, despite having legal authority to protect susceptible populations or environmentally impacted communities, agencies can fail to recognize differences in susceptibility (US EPA 2014). For example, while short-term (5 minute) "peaks" of sulfur dioxide can have adverse effects on exercising asthmatics, the EPA uses a one-hour standard based on a three-year average of exposure. This standard seems to fall short of sufficient protection, but it might also be a result of technical measurement limitations (US EPA 2010). And, protecting susceptible individuals and those in heavily impacted communities can be quite slow to manifest. Following a substantial delay, the US EPA has begun improving protection for farmworkers and children from the pesticide chlorpyrifos, but the rulemaking is not complete (Lehner 2015).

Moreover, political scientists have argued that "agents" in the bureaucracy can fail to carry out legal mandates imposed by their Congressional "principals." Agencies must have the authority, resources, and committed personnel to carry out their obligations. Any break in these links can frustrate legal requirements. Failures might have several explanations: inter alia, "loose" legislative guidance, personal preferences that conflict with or override those of legislators, greater expertise by regulatory agents, simple "shirking," or agency "capture" (Wildavsky 1979; McCubbins et al. 1987; Carpenter \& Moss 2014). Similar explanations likely account for why susceptible subpopulations are not better protected by agencies under some statutes. There could be remedies via administrative or court procedures, and even political pressure on agencies, as McCubbins et al. argue (1987), but to date these seem limited in scope. Indeed, our proposal to make explicit the effects on susceptible groups might somewhat mitigate capture effects, inform those at risk, and assist in better implementation of mandates.

\subsection{How do agencies disaggregate costs in CBA?}

We also find that regulatory agencies tend to incorporate even less information about variability in costs than they do about variability in risk (Robinson et al. 2016; Williams \& Broughel 2015). Except in rare cases, the only information agencies include about interindividual variability in costs borne involves extensive breakdowns of the costs borne by different sectors of affected industry. OSHA, for example, has chosen to make its determinations that a particular proposed regulation is "economically feasible" by estimating the effect of compliance on revenue and profits, broken down by Standard Industrial Classification and often by the size of the firm. However, even this degree of disaggregation is not common to all regulatory agencies. For instance, none of the scholarly articles containing scoring systems for the quality of agency Regulatory Impact Analyses (RIAs) grade RIAs on whether and to what extent each of them provides information on differential costs to various sectors of industry (see, e.g. Hahn \& Dudley 2007). Over time, more RIAs contain such information, but the ability of an agency to produce an RIA graded as "excellent" by researchers, without any information on sectoral costs, may discourage the collection of this information. Moreover, even highly disaggregated information on costs to firms does not directly inform society about the variability in costs to consumers and citizens. At one extreme, these costs could be identical - when demand is perfectly inelastic, all costs to firms translate into proportional price rises, and the citizen can roughly gauge what s/he will pay for the regulatory benefits by assuming all costs are borne in the form of higher sales prices. At the other extreme, all costs are borne by owners, shareholders, and workers in the form of reduced corporate profits. But all intermediate scenarios are also possible, and beyond; for instance, some costs of food safety requirements in the poultry industry were borne in the form of marginal (smaller) 
firms being bought by more efficient (larger) ones - with significant local effects but with virtually no effect on consumer prices (Salin \& Finkel 2013).

\section{How should environmental health agencies incorporate distributions of adverse health effects and adverse economic effects into their CBAs?}

Our short answer to this question is that all citizens are morally significant members of the moral community. Consequently, the economic and non-economic effects on their lives should be registered, recognized, and acknowledged to the extent there is "free" or readily available knowledge, or if the information can be provided at not too great a cost relative to what it reveals. Those who are affected need not be personally identified, as often that degree of specificity would be too analytically demanding. However, if such information is available, it should be incorporated as long as it is otherwise legally and morally permissible to do so (not violating rights to privacy, not used for discriminatory purposes, and so on; see Finkel 2008).

Consequently, we argue two major points in this final section :

- We should model, to the extent feasible, the whole population that is affected by a risk-reducing intervention and try not to use [average harm times the number of people affected] and [average costs to reduce the harm times the number of people or firms affected]. We believe that a proper analysis would reveal that risk and cost functions (disutilities) for individuals are likely to be non-linear.

- Because the most harm on the risk side occurs to the most susceptible or the most exposed, and the greatest costs are borne by those most highly "exposed" to costs or the most susceptible to loss of income/wealth, a useful surrogate for total social benefits versus total social costs might be to compare the most adversely affected subpopulations for both costs and benefits. Appropriate examples of such an approach would have to be considered to see if such a manner of proceeding would be defensible.

Basically, we advocate the development of distributions of risk and cost, either discrete (categorical, with estimates of the proportion of persons and/or firms in each category) or continuous whenever feasible. For an example on the risk side of the ledger, consider the reanalysis by Thompson et al. (2001) of the Goldstein et al. (1992) assertion that the lifetime risk of a US citizen being killed by an airplane crash (while not a passenger on the plane) was 4.2 in one million. ${ }^{9}$ Because this risk was demonstrated to be a very strong (inverse) function of distance from the nearest airport runway, analysts could choose to model this risk as a continuous function, or at least to dichotomize it into the categories in Thompson et al. ("less than 2 miles" and "greater than 2 miles," with the risk to citizens in the first stratum more than 10,000 times greater than the second). On the cost side, the general principles discussed in Section 3.2 can shed much light on how non-uniform the distribution of actual regulatory costs is likely to be. The analyses in Harrington et al. (2014) are very much in the spirit of showing how cost (and benefit) estimates could be meaningfully disaggregated across various population covariates, showing that many policies that produce a small total excess of benefits over costs in actuality produce large individual gains for "winners" and large individual losses for others.

The higher the stakes of a decision, or the broader the divergences between low and high-risk individuals (or similar divergences on the cost side), the more important it is to disaggregate impacts. For low-stakes decisions, or where the analysis supports prioritization of subsequent control efforts or the screening of problems, doing much more than a one-size-fits-all analysis may not be worth the effort - but even in these cases, it may be important to realize that a "small" problem, or an "unlikely to be important" substance, may look rather different if it affects a subpopulation intolerably.

As important as we think it is to communicate risks and costs in a manner relevant to individual citizens and their circumstances, this is only half of the problem with the status quo: what remains is the haphazard and sometimes odd way we value changes in risk and in wealth. Whether by design or by default, analysts and decisionmakers cannot avoid assigning a "damage function" that relates the harm done by (the disutility of) each change in risk or wealth - and as with many things in the realm of social policy, sometimes the assumptions we make tacitly are the most precarious of all. To simplify this discussion somewhat, consider both risk and cost in three qualitative regions: (i) the smallest changes in risk or cost, which might be treated as de minimis and, hence, assigned no disutility or damage; (ii) the bulk of the circumstances, where changes in risk or wealth are clearly palpable and might be 
valuated in a linear fashion as they increase; and (iii) the "intolerable risk/intolerable cost" region at the top of each scale, where it is conceivable that the damage function must rise steeply, or reach an asymptote of essentially infinite value, in order to effectuate society's extreme aversion to consequences of this severity. Combining these three regions yields, for either risk or cost, an analogy to the "reporting function" (Oswald 2008). Mishandling this valuation step is as fatal to good public policy as misestimating the aggregate risk or cost itself. Indeed, the entire revolution that overturned expected-value decisionmaking more than 250 years ago, in favor of expected utility, was the simple observation that the consequences of changes in wealth or health are often non-linear in their magnitude (Bernoulli 1738).

In the region where individual risks or costs are lowest, society should avoid two possible logical errors: (i) giving some risks or costs less weight than those who bear them would give them (e.g. treating as trivial something not trivial to the affected party); or (ii) giving some risks or costs more weight than they deserve (e.g. treating as non-zero - and, hence, amenable to "adding up to a whole lot" when tallied across a large population - changes in risk or wealth that no individual affected would regard as non-zero).

At the low end of the risk range, regulatory agencies and most commentators assume that there exist de minimis risks, a level below which there is no social need to consider them. A hypothetical exposure that would subject every American citizen to an excess lifetime risk below 1/million would never become the subject of regulatory action no one would be "harmed" enough to count for anything, even though as many as 300 statistical lives would be expected to be lost nationwide at this risk level. But at the same time, we generally do not assume that there are de minimis regulatory costs that are too low to include in an analysis. An ordinary example of this is illustrated by the cost of gasoline. If the price of gas goes up by one-tenth of a penny per gallon, that corresponds to a cost of about 50 cents per year for a driver who buys 10 gallons of gas a week. But if this change applies to 150 million drivers, the total national cost of that tiny increase in the gas price is more than $\$ 75$ million per year. Which estimate - $\$ 75$ million or zero (the summation of a large number of completely inconsequential impacts) - is more correct? The most fundamental logic of CBA is that physical harms can be compared to monetary harms, in the common currency of currency. If we really believe that, then we should not discard some risks that are "too small to matter" and at the same time count their equivalent costs as "too large not to matter." To rectify this asymmetry, we can see good arguments either for adding a notion of de minimis costs to regulatory economics, or for abandoning the notion of de minimis risk. If risks below $1 /$ million are too small to matter, then 300 statistical lives lost in the US over 70 years are, by definition, too small to matter as well. But at the current valuation of approximately $\$ 7$ million per statistical life, this is exactly the same as saying that any nationwide regulatory cost of less than $\$ 30$ million per year is also too small to matter. Yet this sum is larger than the current threshold for a "major rulemaking" (a cost of $\$ 100$ million, but accrued over the lifetime of the regulation, which corresponds to an annualized cost of roughly $\$ 4$ million per year if annualized over 20 years at a 3 percent discount rate; and there are bills pending in Congress as of this writing that would halve this threshold). This way of looking at the example seems to favor the status quo for cost, which is to allow no de minimis exclusion for "small" costs. In this case, we argue strongly that society should also count "small" risks - that is, extend the probability density function for risk to the left of $1 /$ million, and let these very small risks add to the total amount of risk, rather than censoring the risk distribution and ignoring them.

At the "intolerable" end of the risk and cost range, we perceive a different asymmetry in current official practice, and are troubled by various "unofficial" impositions of non-linearity. It should be clear, we contend, that equal increases in individual risk or cost are more dire as the amount of risk (cost) increases. On the risk side of the ledger, someone willing to pay only $\$ 7$ to avert a risk of $1 /$ million would certainly be willing to pay (if her budget allowed) far more than $\$ 700,000$ to buy out of a forced game of Russian Roulette with a risk of $1 / 10$. Every researcher who has contributed to the value of statistical life (VSL) literature has emphasized (at least in a footnote...) that statedpreference estimates of the VSL are never meant to apply to "large" risks, but only to "small" ones (e.g. Hammitt \& Treich 2007; Viscusi 2012). For example, Viscusi (2007, p. 114) notes:

[T] he VSL will understate how much people must be compensated to face a series of increases in fatality risk that culminate with certain death.

But no agency has ever developed a quantitative method for assigning larger weight to intolerable risks - instead, they multiply average risk times population size times the VSL, regardless of how long the right tail of the risk distribution is. Although an agency might have an idea of a maximum individual risk they will tolerate, such an all-or-none approach 
falls prey to both of the two logical mistakes: it can lead to unnecessary regulatory stringency by treating risks to a very small minority as more important than the benefits of the risky activity to the majority, or it could lead to insufficient protection by lowering the risk to the minority to "acceptable" levels but ignoring large (but not wholly "intolerable") risks to many just below the arbitrary line. ${ }^{10}$ This discrepancy highlights the need for a consensus approach to assessing how much more steeply than linear the "risk versus harm" function rises when individual risks rise above roughly 1/1000 - not as a way to merely decree that some risks are intolerable, but to quantify how intolerable they (and slightly smaller risks) are.

On the cost side, the default position similarly treats a given amount of cost as $1 / \mathrm{N}^{\text {th }}$ as adverse as a cost $\mathrm{N}$ times higher, no matter how large the cost becomes. Again, economists almost unfailingly agree that money has diminishing marginal utility (DMU; e.g. Fennema \& van Assen 1998, but for a rare contrary view, see Frankfurt 2015) - which is the same as saying that the incremental degree of harm done by taking $\$ 1$ to implement some common social purpose, like a regulation, increases steeply as more and more resources are required from each person. However, this dictum (which we suggest could be recast in the regulatory context as "the increasing marginal disutility of cost") is routinely ignored in CBA (Robinson et al. 2016). Moreover, the DMU of money also means that each citizen will have a different nonlinear function as she considers a point where her contribution will become particularly adverse. Thus, the actual "cost" of a (say) \$1 billion social program cannot be estimated without gathering data on (or making informed distributional assumptions about; see Finkel 2016) what costs are borne by whom, and how they weigh those costs - and yet utility and distributional effects in both instances are treated casually, if at all (Adler 2013). Here, however, is one instance where (part of) Europe seems to be ahead of the US - the United Kingdom "Green Book" details how to compute "equivalised income" across five income quintiles, in order that distributional weights could be applied to the costs of a policy and to favor proposals imposing lower costs on the lowest-income groups (Her Majesty's Treasury 2011, p. 92). Nevertheless, even here, information on the relative prosperity of those bearing identified costs is deemed "most unlikely to be available at acceptable cost for many applications," so the distributional adjustments are voluntary.

And in practice, both in the US and the EU, there is an important difference between how these two linear functions are actually modified on the cost side of the ledger versus the risk side. When costs are at issue, examples abound where intolerable economic harm to individuals becomes the focus of agency, legislative, judicial, or public attention - when, to be colloquial about it, "the squeaky wheel gets the grease." In contrast, on the risk side we have no quantitative reference points for when the "tail risk" can or should dominate all other considerations - if it happens, it is a function of access to political power and the poignancy of the concern. For an example, more and more school districts are banning peanut products from cafeterias: their concern is not with the small increments of foregone benefit to tens of thousands of students who might enjoy peanuts, but with the averted risks to a small minority who might have a severe anaphylactic reaction. But while environmental justice expresses concerns about risks to especially susceptible subpopulations, it is not clear whether and how much this has been incorporated into risk assessments. In contrast, we do have benchmarks on the cost side: the amount of cost to individual firms that can push them toward bankruptcy or severe competitive disadvantage (OSHA's rule of thumb, e.g. is that costs exceeding ten percent of profits or one percent of revenue are prima facie of special concern). We see special concerns for "tail costs" everywhere - in the form of regulatory variances for vulnerable businesses, longer compliance schedules, flat-out exemptions, and even Congressional appropriations riders enjoining agencies against enforcing standards against firms in certain sectors and/or of certain size categories (Copeland 2008). Again, these accommodations tend to be all-or-none, both in the US (SBREFA) and the EU. In Europe, the "SME Test" for Small and Medium Enterprises has become routine; it similarly recommends wholesale exemptions, as opposed to any conclusion that subjecting these businesses to the same requirements as others represent costs that are amply justified by the regulatory benefits (European Commission 2015b).

To summarize the discussion so far, Figure 1 shows how we generally do construe the function relating risk or cost to harm done. For risk, there is a de minimis region where non-zero risk confers zero harm, and then a linear region where harm is proportional to risk. At the extreme right-hand portion of the graph, the function stops - not because we routinely give special weight to incredibly high risks, but because no risk can exceed $100 \%$ certainty. For cost, the linear function extends all the way to the origin (no de minimis region), and sometimes (not always) cuts off at some idiosyncratic value that represents "certain death" at the firm level, or perhaps an amount of cost that firms or their trade associations can argue makes bankruptcy too likely to allow.

Figure 2 shows one possible way to improve and reconcile the treatments of risks and costs: it allows for either to be de minimis, and then to follow a convex (upward-sloping) function so that as risks or costs rise, concern rises in steeper 

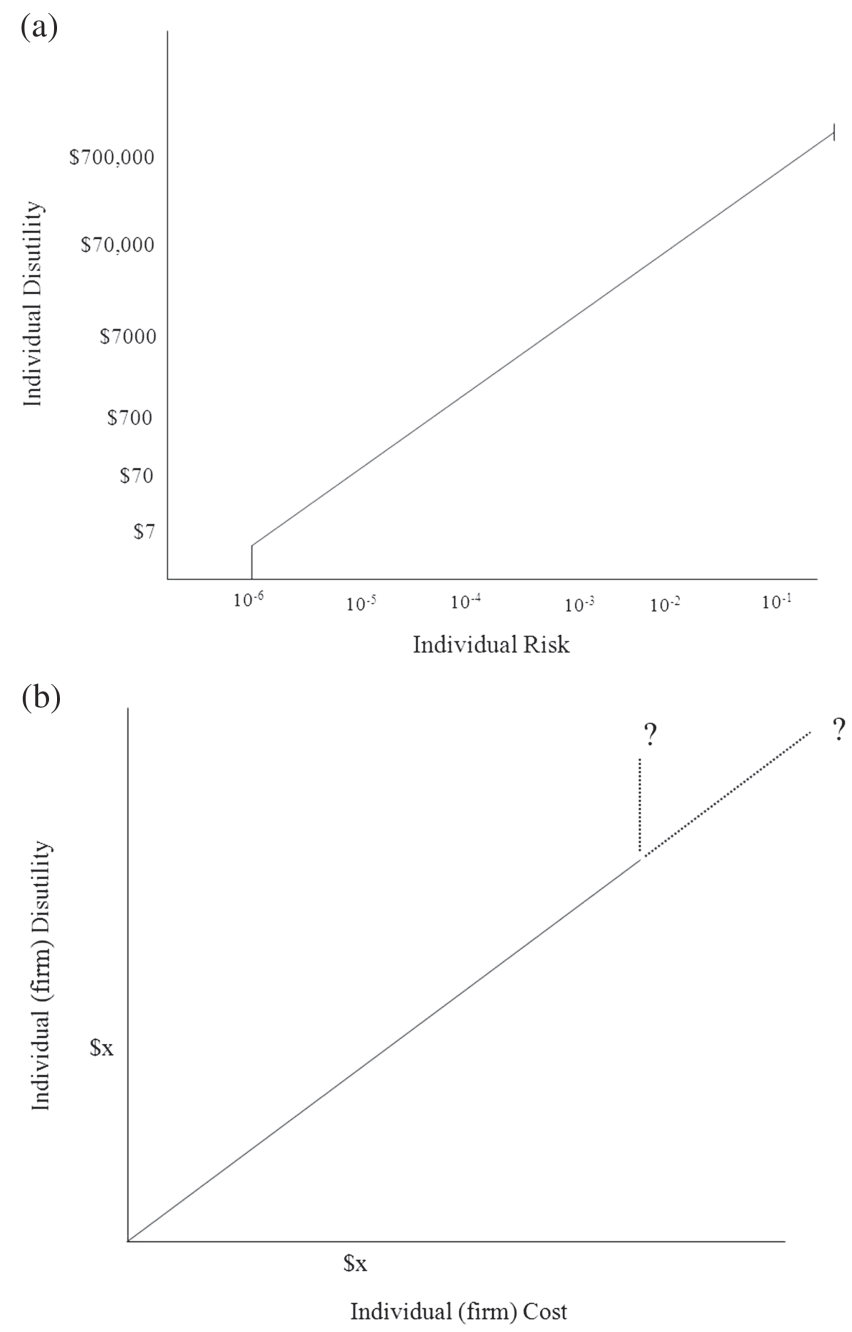

Figure 1 (a) A schematic showing how American federal regulatory agencies generally valuate the harm done to any individual as a function of individual risk; risks below $10^{-6}$ are treated as de minimis (assigned zero value to reduce or eliminate), while above this threshold the disutility of a risk is treated as linear in the magnitude of risk (e.g. if willingness to pay to eliminate a risk of $10^{-5}$ is estimated at $\$ 70$, the "value of a statistical life" is estimated as $\$ 7,000,000$, and the value of eliminating a risk of $10^{-1}$ is estimated as $\$ 700,000$ ). (b) A schematic showing how agencies generally treat the harm done to an individual as a function of the cost imposed by a regulation - there is no de minimis region, but sometimes costs above a large amount are de facto treated as intolerable, and regulations imposing such costs are deemed infeasible (or firms facing such costs are given variances from having to comply with them).

and steeper proportion. Armed with a distribution of individual (or subpopulation) risks and one of costs, agencies (and their critics and overseers) could integrate (in the mathematical sense of summing each increment of risk or cost, appropriately monetized by a function such as the ones in Fig. 2) the distributional information at their disposal and arrive at an estimate of total benefits and costs that was faithful to the interindividual differences in personal circumstances and how they manifest as differential harm.

Even such a disaggregated formulation of cost and benefit, however, still leaves out one important dimension - that of susceptibility, a phenomenon that exists on both sides of the risk/cost ledger. The effect of baseline differences in genotype and disease status, on one side, and of baseline wealth on the other, means that the curves in Figure 2 (one for risk and one for cost) are really a family of curves, depending upon where the post-regulatory "exposure" (again, to risk or to cost) level is set and the susceptibility within the group. If exposures are set at a level that keeps risks for those with average exposure and average susceptibility near or just above the de minimis level, they and all less vulnerable groups will be protected (Finkel 2014b). However, it is likely that the most susceptible group will have much higher than de minimis risks. This is illustrated qualitatively in Figure 3a, which shows that for a given level of exposure, the most susceptible subgroup experiences intolerable risks, an intermediately exposed or intermediately susceptible 


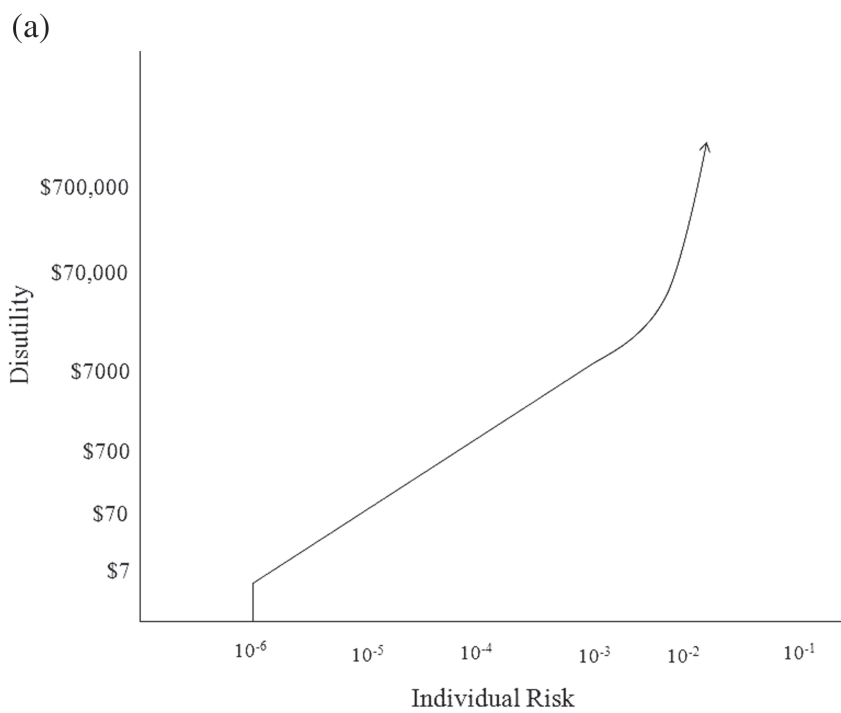

(b)

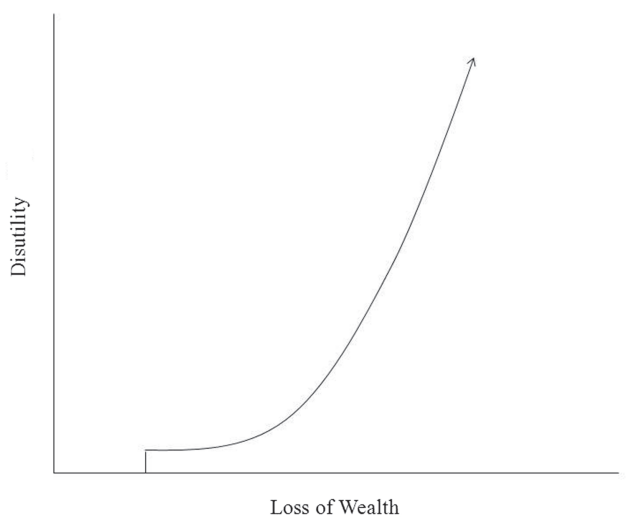

Figure 2 (a) One possible way to improve the treatment of individual risks: retain the de minimis region, but allow large risks to carry valuation that rises more steeply than linear as the probability of death becomes intolerably high. (b) One possible way to improve the treatment of individual costs: impose a de minimis region, and allow large costs to carry large, but not infinite, valuation.

group experiences thousands of dollars of harm per person, and the least exposed or least susceptible perhaps zero or de minimis risks. Similarly, on the cost side, because of the diminishing marginal utility of money, taking some fixed amount (say, \$1,000) from everyone affected to pay for the elimination or reduction of risks to fellow citizens is de minimis to the richest subgroup, but intolerable to the poorest. Thus, the breakdown of the effects of costs on different subgroups in the population reveals much more than merely the total cost of a given health or safety intervention.

\section{Concluding remarks}

Advances in both biology and the analytic ability to represent costs and benefits have outstripped how risk-cost-benefit analyses are typically conducted. Thus, there is both a moral and public-information case to be made for disaggregating adverse health effects and costs as they affect major subgroups of citizens. Groups on both sides of the CBA ledger should be properly represented in CBA, and both they and the larger public should understand how the different subgroups in the population are affected by regulatory interventions. We have stressed the distribution of risk or cost per se -whether anyone bears risk or cost far above (or far below) the average - rather than the typical way "equity" is construed and delimited, which is to ask only whether subgroups with defined characteristics unrelated to risk or cost (their race, age, etc.) are disproportionately impacted. Indeed, the UK Green Book explicitly disclaims interest in the tail of the individual-risk distribution, precisely because "non-monetary costs and benefits (e.g., life, health, etc.) are not adjusted as they are considered to be independent of income" (Her Majesty's Treasury 2011, p. 92; footnote 3, emphasis added). Of 
(a)

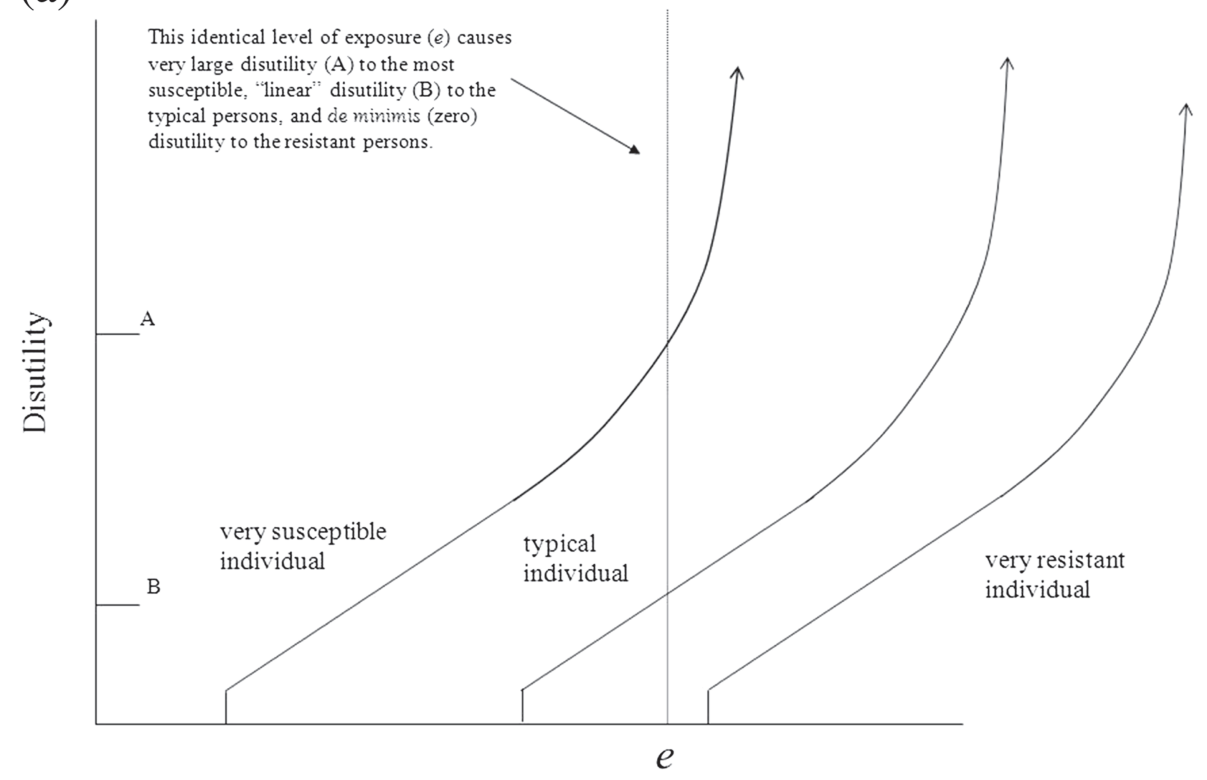

Exposure (note change of axis from "risk")

(b)

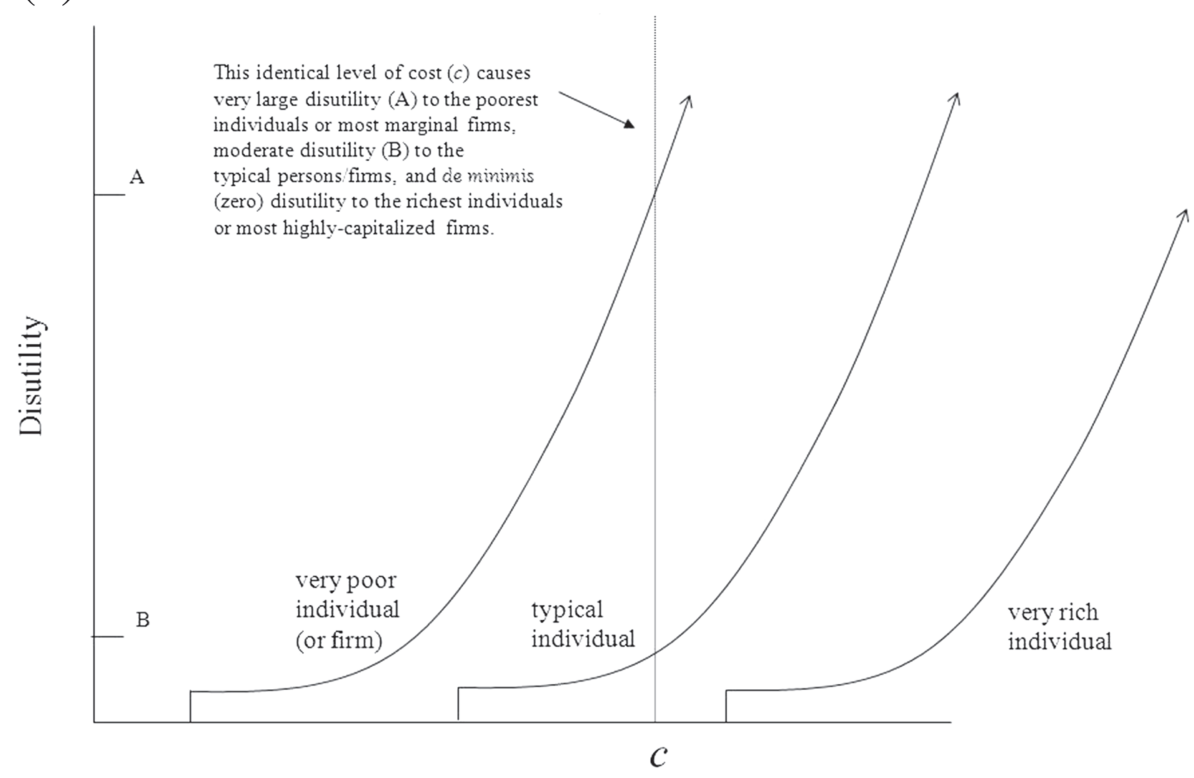

Loss of Wealth

Figure 3 (a) A family of the curves in Figure 2a, showing how different individuals, with different susceptibilities, will face different levels of harm at any given level of exposure (i.e. any regulatory concentration limit). (b) The analogy to Figure 3a on the "cost" side of the ledger: instead of different susceptibility, the factor distinguishing individuals (or firms) from each other is their income (or wealth).

course there will often be correlations between the existence of tail risks/costs and the makeup of the groups within them, and policymakers should not be blind to these correlations, but we are suggesting that analysts should trace risks and costs as they are diffused throughout society, rather than to look sequentially at particular groups and see whether or not they happen to be disparately affected. ${ }^{11}$

Both US and EU agencies overwhelmingly tend - when they look at distribution at all - to do it the latter way. As a practical matter, they also tend to perform distributional analysis after the "main" CBA, and ancillary to it; this likely relegates distributional concerns to matters that can "tweak" a determined outcome, rather than ones that can 
fundamentally shape outcomes. In the US, a typical conclusion about this states that "agency analysts should keep distributional issues separate from issues of economic efficiency, so as not to confuse decision makers about these different decision inputs" (Williams \& Broughel 2015, p. 4). Similarly, the Green Book relegates distributional concerns to an Annex (\#5). Shapiro (2011) argues, and we agree, that one-paragraph dismissals of the mandatory "must consider" categories (Indian tribes, children, etc.) serve no one. There is a principled belief that policies to redistribute costs and benefits to offset adverse distributional effects of health/safety/environmental regulation should be developed and implemented outside of those agency regulations (e.g. in tax policy or in job re-training programs), but again, we emphasize here that such second-order policies can never progress beyond idle musings unless and until the quantitative analysis of the distributional effects of regulation are actually undertaken.

We are acutely aware of the analytic complexity and data requirements for full individualization of risk and cost. By suggesting a goal of individualization, we offer a way to "work backwards" from the pinnacle of analysis, and to defer or reject complexities that are truly beyond our abilities. Reasonable assumptions about the shape and breadth of the interindividual distributions of risk and cost can often follow readily from data already collected in traditional regulatory analyses (e.g. the extensive tabulations in US EPA 2011 on how exposure depends on age, sex, race, income, and region; the estimates of demand elasticity that are needed to justify findings of economic feasibility for firms can be used to trace costs to consumers as well). Other information (e.g. the default distribution of interindividual variability in susceptibility to carcinogenic stressors in the human population, see NRC 2009, Chapter 5) is generic to many analyses. Importantly, even if distributional information is not already available, it still may be necessary to collect it in order to correct inaccuracies in conventional "the mean is all that matters" cost-benefit determinations, because for many distributed quantities, one cannot accurately estimate the expectation without information on the length of the right-hand tail (see Finkel 1990 for an explanation of how the mean of a lognormal distribution is strongly influenced by the length of the tail).

The second-best alternative to full individualization, noted earlier, is to focus only on the tails of each distribution, but to do so with eyes open and with a premium on balance, so that decisionmakers do not hear exclusively from those most at risk or those with the most to gain by thwarting regulation. In one sub-domain of environmental policy, the question of the effects of regulation on employment, a recent book documents that policymakers are indeed focusing on both tails at once, but only because believers in "job-killing regulations" and optimists about the "green jobs" effect of regulation are vying for who can take a more extreme position (Coglianese et al. 2014). The great advantage of putting more effort into careful analysis not just of the tails, but also of the entire distribution, is that it has the potential to replace this cacophony with deliberation.

Some thoughtful scholars have proposed that we replace CBA entirely with a method that expresses both sides of the ledger in common units of "well-being" (e.g. Adler 2012; Bronsteen et al. 2013). Despite our interest in those ideas, "well-being analysis" may be too radical to be accepted by the federal and state regulatory agencies, which have advanced CBA methods over several decades, and the Office of Information and Regulatory Affairs, which has an abiding interest in traditional CBA. Well-being analysis also requires difficult-to-elicit information about how changes in individuals' health status affect the marginal utility of consumption (Finkelstein et al. 2009). Instead, we propose intermediate, incremental, and more palatable solutions to expressing, in a balanced way, the complex experience of risks and dollars while retaining the common currency of money to express both.

\section{Acknowledgements}

The authors gratefully acknowledge that full support for this article was provided by the Decision, Risk, and Management Sciences Program, U.S. National Science Foundation, under Award SES-0756539. We also appreciate the helpful comments of two anonymous reviewers, and the productive discussions we had with scholars in the EU (Ragnar Lofstedt, Andrea Renda, and Jacopo Torriti). Catherine A. O’Neill provided helpful comments and references.

\section{Notes}

1 In this article, we define "benefits" to be "all of the changes (both positive and negative) in outcomes not traded in markets" (Finkel 2014a). These include the health, safety, environmental, and other harms that are reduced by a regulation, that are then monetized. In contrast, "costs" are "all of the changes, impelled by the regulation(s), in resources that are traded in markets-in other words, the costs are the resources that are consumed or reallocated so that society can 'buy' the benefits." In more succinct 
language, "the benefits are the results of the intervention and the costs are the resources marshaled to attain them" (Finkel 2014a, p. 97). There are many other ways to parse the costs of a policy intervention from its benefits (the most common of which is probably to define the former as all the negatives and the latter as all the positives), but we believe this pair of definitions is the most coherent and useful way.

2 Even if there is no information in a particular case about which sorts of people are most affected, there still remains a difference between: (i) a situation where government knows no compensation at all is needed (all share equally in benefits and costs); and (ii) a situation where there are clearly large transfers of welfare. For one thing, in the latter case, more effort might be expended to figure out who has won and lost.

3 Although later (Sec 3.2) we will argue that policies made in light of distribution might be different even without any information about the kinds of persons most affected, it is also possible that fragmentary distributional information could promote "imperfect compensation." For example, a regulation might be seen to affect rural areas in general, and so government might increase aid to rural communities to partially offset this effect, even knowing that some unaffected communities will receive aid they did not "need" so that others will. The general point is that just as benefit-maximization can be imperfect, so can second-order policies involving compensation (more generally, "redress") - but imperfect redress may be preferable to none at all.

4 Note that in the former situation, one "statistical life" is expected to be lost, whereas in the latter, twice as many deaths are expected.

5 The sweeping change to the Toxic Substances Control Act, passed by Congress and signed into law by President Obama on June 22, 2016 ("The Frank R. Lautenberg Chemical Safety for the $21{ }^{\text {st }}$ Century Act"), requires the EPA Administrator to certify that a new substance or new use of a substance will not pose an unreasonable risk to human health, including to "potentially susceptible populations identified as relevant by the Administrator."

6 Although many OSHA health standards strive to reduce individual risks to tolerable levels for an undefined "average" worker exposed to the permissible exposure limit (PEL) for a working lifetime, a few OSHA standards explicitly strive to protect workers of above-average susceptibility. For example, the 1997 methylene chloride standard models the interindividual distribution of how adults metabolize methylene chloride into its carcinogenic intermediates, and sets the PEL based on the risk to a worker whose metabolism places him at the $95^{\text {th }}$ percentile of the population in this regard (OSHA 1997).

7 Note that the Dodd-Frank Wall Street Reform and Consumer Protection Act, enacted in 2010, now also requires the new Consumer Financial Protection Bureau (CFPB) to conduct small business panels, along with EPA and OSHA.

8 Indeed, one of us recently suggested that Congress amend SBREFA to require the three covered agencies to also convene mirrorimage panels on the benefits of regulating small and other businesses (OSHA could empanel employees of small businesses, EPA could empanel residents who live near small businesses that pollute, or CFPB could empanel customers of small mortgage lenders or credit issuers). The agencies could, of course, volunteer to take such testimony without a statutory requirement (Finkel 2011).

9 Note that both of these articles considered a database of fatal crashes that all long preceded the September 11, 2001, tragedy, and involved the unintentional grounding of airplanes.

10 By definition, a regulation cannot be stringent enough if it talks about intolerable risk but then fails to avert it. OSHA, for a case in point, has repeatedly written that the US Supreme Court's interpretation of its governing statute means that an individual lifetime excess risk of $1 / 1000$ is "the uppermost end of a million-fold range, somewhere below which the boundary of acceptable versus unacceptable risk must fall.” And yet nearly all of OSHA's health standards fail to reduce the average risk to workers to below 1/ 1000; its two most recent health standards leave behind an excess risk of lung cancer of between 10 and 45 chances per 1000 (OSHA 2006) and of between 18 and 26 chances per 1000 (OSHA 2016).

11 Depending on how one looks at it, attention paid to income/wealth is an important instance where analysis and policy should pay specific attention to a characteristic other than "distribution per se," but this is because of the direct connection between wealth and the effect of regulatory cost on personal welfare.

\section{References}

Adler MD (2012) Well-being and fair distribution: Beyond cost-benefit analysis. OUP, New York.

Adler MD (2013) Cost-Benefit Analysis and Distributional Weights: An Overview. Duke Environmental and Energy Economics Working Paper Series, EE 13-04, August 2013. Nicholas Institute for Environmental Policy Solutions/Duke University Energy Initiative, Durham, NC.

Anthes E (2010) "Hey Would-Be Daddies, How You Take Care of Yourself Plays into the Health of Your Future Children.” [Last accessed 15 July 2016.] Available from URL: http://www.alternet.org/story/149200/hey_would-be_daddies2C_how_you_take_ care_of_yourself_plays_into_the_health_of_your_future_children

Ashford NA (2005) Incorporating Science, Technology, Fairness, and Accountability in Environmental, Health, and Safety Decisions. Human and Ecological Risk Assessment 11, 85-96.

Barlow BK, Cory-Slechta DA, Richfield EK, Thiruchelvam M (2007) The Gestational Environment and Parkinson's Disease: Evidence for Neurodevelopmental Origins of a Neurodegenerative Disorder. Reproductive Toxicology 23, 457-470.

Bernoulli D (1738) Exposition of a New Theory on the Measurement of Risk (translated and reprinted in Econometrica 22 (January 1954)), 23-36.

Bronsteen J, Buccafusco C, Masur JS (2013) Well-Being Analysis vs. Cost-Benefit Analysis. Duke Law Journal 62, $1603-1689$.

Carpenter D, Moss DA (eds) (2014) Preventing Regulatory Capture: Special Interest Influence and How to Limit It. CUP, Cambridge, MA. Coglianese C, Finkel AM, Carrigan C (eds) (2014) Does Regulation Kill Jobs? University of Pennsylvania Press, Philadelphia. 
Copeland CW (2008) Congressional Influence on Rulemaking and Regulation through Appropriations Restrictions. Congressional Research Service Report for Congress, Updated August 5, 2008, RL34354.

Crain NV \& Crain WM (2010) The Impact of Regulatory Costs on Small Firms, U.S. Small Business Administration, Office of Advocacy SBAHQ-08-M-0466, Easton, PA.

Cranor CF (1997) Eggshell Skulls and Loss of Hair from Fright: Some Moral and Legal Principles that Protect Susceptible Subpopulations. Environmental Toxicology and Pharmacology 4, 239-245.

Cranor CF (2011) Legally Poisoned: How the Law Puts Us at Risk from Toxicants. Harvard University Press, Cambridge, MA.

Dietert RR, Piepenbrink MS (2006) Perinatal Immunotoxicity: Why Adult Exposure Assessment Fails to Predict Risk. Environmental Health Perspectives 114, 477-483.

Dietert RR, Zelikoff JT (2010) Identifying Patterns of Immune-related Disease: Use in Disease Prevention and Management. World Journal of Pediatrics 6, 111-118.

Earthjustice (2014) Defending Fenceline Communities from Oil Refinery Pollution. [Last accessed 15 July 2016.] Available from URL: http://earthjustice.org/our_work/cases/2014/defending-fenceline-communities-from-oil-refinery-pollution

European Commission (2015a) Better Regulation Guidelines. European Commission, Strasbourg, France.

European Commission (2015b) Better Regulation Toolbox-Tool \#19: The "SMETEST." [Last accessed 15 July 2016.] Available from URL: http://ec.europa.eu/smart-regulation/guidelines/tool_19_en.htm

Executive Order of the President No. 12898 (1994) Federal Register Vol. 59 No. 32, February 16, 1994. [Last accessed 15 July 2016.$]$ Available from URL: http://www.archives.gov/federal-register/executive-orders/pdf/12898.pdf

Fennema H, van Assen M (1998) Measuring the Utility of Losses by Means of the Tradeoff Method. Journal of Risk and Uncertainty 17, 277-295.

Finkel AM (1990) A Simple Formula for Calculating the "Mass Density" of a Lognormally Distributed Characteristic: Applications to Risk Analysis. Risk Analysis 10, 291-301.

Finkel AM (1997) Not to Decide is to Decide: Ignoring Susceptibility is not "Good Science". Environmental Toxicology and Pharmacology 4, 219-227.

Finkel AM (2008) Protecting People in Spite of —or Thanks to-the "Veil of Ignorance". In: Sharp RR, Marchant GE, Grodsky JA (eds) Genomics and Environmental Regulation: Science, Ethics, and Law, pp. 290-342. Johns Hopkins University Press, Baltimore.

Finkel AM (2011) The Regulatory Flexibility Act Improvements Hearing: Testimony of Adam M Finkel before the U.S. House of Representatives Committee on Small Business, June 15, 2011. [Last accessed 15 July 2016.] Available from URL: http:// smallbusiness.house.gov/uploadedfiles/finkel_testimony.pdf

Finkel AM (2013) Protecting the Cancer Susceptibility Curve. Environmental Health Perspectives 121, A238.

Finkel AM (2014a) The Cost of Nothing Trumps the Value of Everything: The Failure of Regulatory Economics to Keep Pace with Improvements in Quantitative Risk Analysis. Michigan Journal of Environmental and Administrative Law 4, 91-156.

Finkel AM (2014b) EPA Underestimates, Oversimplifies, Miscommunicates, and Mismanages Cancer Risks by Ignoring Human Susceptibility. Risk Analysis 34, 1785-1794.

Finkel AM (2016) “I Thought You'd Never Ask: Structuring Regulatory Decisions to Stimulate Demand for Better Science and Economics." Manuscript in review. European Journal of Risk Regulation.

Finkelstein A, Luttmer EFP, Notowidigdo MJ (2009) Approaches to Estimating the Health State Dependence of the Utility Function. American Economic Review: Papers and Proceedings 99, 116-121.

Fisher E (2007) Opening Pandora’s Box: Contextualising the Precautionary Principle in the European Union. Oxford Legal Studies Research Paper, No. 2/2007. University of Oxford, Oxford.

Fox M (2015) Five Things to Know about the EPA's New Rule for Oil Refineries. Earthjustice, Nov 6. [Last accessed 15 July 2016.$]$ Available from URL: http://earthjustice.org/blog/2015-november/5-things-to-know-about-the-epa-s-new-rule-for-oil-refineries Frankfurt HG (2015) On Inequality. Princeton University Press, Princeton, NJ.

Friedman R (1981) Sensitive Populations and Environmental Standards: An Issue Report. Conservation Foundation, Washington, DC.

Fullerton D (2011) Six Distributional Effects of Environmental Policy. National Bureau of Economic Research Working Paper No. 16703. NBER, Cambridge, MA.

Fullerton D \& West S (2003) Public Finance Solutions to Vehicle Emissions Problems in California. Berkeley Electronic Press, Berkeley. [Last accessed 15 July 2016.] Available from URL: http://services.bepress.com/cgi/viewcontent.cgi?article $=1000 \& c o n t e x t=$ fullertonwest

Ginsburg DH, Menashi S (2010) Nondelegation and the Unitary Executive. University of Pennsylvania Journal of Constitutional Law 12, 251-276.

Goldstein BD, Demak M, Northridge M, Wartenburg D (1992) Risk to Groundlings of Death Due to Airplane Accidents: A Risk Communication Tool. Risk Analysis 12, 339-41.

Grandjean P, Landrigan P (2006) Developmental Neurotoxicity of Industrial Chemicals. Lancet 368, 2167-2178.

Hahn RW, Dudley PM (2007) How Well Does the U.S. Government Do Benefit-Cost Analysis? Review of Environmental Economics and Policy 1, 192-211. 
Hammitt JK, Treich N (2007) Statistical vs. Identified Lives in Benefit-Cost Analysis. Journal of Risk and Uncertainty 35, $45-66$.

Harrington W, Safirova E, Coleman C, Houde S \& Finkel AM (2014) Distributional Consequences of Public Policies: An Example from the Management of Urban Vehicular Travel. Resources for the Future Discussion Paper RFF-DP-14-04. RFF, Washington, DC.

Hattis D (1997) Human Variability in Susceptibility: How Big, How Often, for What Responses to What Agents? Environmental Toxicology and Pharmacology 4, 195-208.

Hattis D, Barlow K (1996) Human Interindividual Variability in Cancer Risks: Technical and Management Challenges. Human and Ecological Risk Assessment 2, 194-220.

Hattis D, Goble R, Chu M (2005) Age-Related Differences in Susceptibility to Carcinogenesis II: Approaches for Application and Uncertainty Analyses for Individual Genetically Acting Carcinogens. Environmental Health Perspectives 113, 509-516.

Health Assembly of the American Thoracic Society, Committee of the Environmental and Occupational Health Assembly (1996) Health Effects of Outdoor Air Pollution, 3-50.

Her Majesty's Treasury (2011) The Green Book: Appraisal and Evaluation in Central Government, London.

Hershleifer J (1980) Price Theory and Applications, 2nd edn. Prentice-Hall, Englewood Cliffs, NJ.

Institute of Medicine (2006) Valuing Health for Regulatory Cost-Effectiveness Analysis. National Academies Press, Washington, DC.

Kysar DA (2010) Regulating from Nowhere: Environmental Law and the Search for Objectivity. Yale University Press, New Haven.

Lehner P (2015) After 15 Years, EPA Finally Moves to Ban Brain-damaging Pesticide Chlorpyrifos. Earthjustice, Dec 7. [Last accessed 15 July 2016.] Available from URL: http://earthjustice.org/blog/2015-december/after-15-years-epa-finally-moves-to-ban-braindamaging-pesticide-chlorpyrifos

Linder SH, Marko D, Sexton K (2008) Cumulative Cancer Risk from Air Pollution in Houston: Disparities in Risk Burden and Social Disadvantage. Environmental Science \& Technology 42, 4312-4322.

McCubbins MD, Noll RG, Weingast BR (1987) Administrative Procedures as Instruments of Political Control. Journal of Law, Economics, and Organization 3, 243-277.

NRC (National Research Council) (1994) Science and Judgment in Risk Assessment. National Academies Press, Washington, DC.

NRC (National Research Council) (2009) Science and Decisions: Advancing Risk Assessment. National Academies Press, Washington, DC.

OSHA (Occupational Safety \& Health Administration) (1997) Occupational Exposure to Methylene Chloride: Final rule. Federal Register 62, 1494-1619.

OSHA (Occupational Safety \& Health Administration) (2006) Occupational Exposure to Hexavalent Chromium: Final rule. Federal Register 71, 10100-10385.

OSHA (Occupational Safety \& Health Administration) (2016) Occupational Exposure to Respirable Crystalline Silica: Final Rule. Federal Register 81, 16286-16890.

Oswald AJ (2008) On the Curvature of the Reporting Function from Objective Reality to Subjective Feelings. Economic Letters 100, 369-372.

Pizer WA, Kopp R (2003) Calculating the Costs of Environmental Regulation. Resources for the Future, Discussion Paper 03-06. RFF, Washington, DC.

Rawls J (1971) A Theory of Justice. Harvard University Press, Cambridge, MA.

Renda A (2011) Law and Economics in the RIA World. Erasmus University, Rotterdam.

Renda A, Schrefler L, Luchetta G, Zavatta R (2013) Assessing the Costs and Benefits of Regulation. Study for the European Commission. Secretariat General, CEPS, Brussels.

Robinson LA, Hammitt JK, Zeckhauser R (2016) Attention to distribution in U.S. regulatory analyses. Review of Environmental Economics and Policy 10(2), 308-328.

Salin V, Finkel AM (2013) Variability in Costs to Comply with Regulations: An Application To Food Safety. [Last accessed 15 July 2016.] Available from URL: https://sites.google.com/a/adamfinkel.com/nsfprojectoutputs/home

Shapiro S (2011) Defragmenting the Regulatory Process. Risk Analysis 31, 893-901.

Shapiro S, Goodwin J (2013) Distorting the Interests of Small Business: How the Small Business Administration Office of Advocacy's Politicization of Small Business Concerns Undermines Public Health and Safety. Center for Progressive Reform, White Paper \#1302, January 2013, Washington, DC.

Stern J, Wiener JB (2006) Precaution Against Terrorism, KSG Working Paper No. RWP06-019. Harvard Kennedy School of Government, Cambridge, MA.

Sunstein CR (2002) Risk and Reason: Safety, Law, and the Environment. CUP, Cambridge, UK.

Sunstein, CR (2012) The Stunning Triumph of Cost-Benefit Analysis. BloombergView 12 Sep. [Last accessed 15 July 2016.] Available from URL: https://www.bloomberg.com/view/articles/2012-09-12/the-stunning-triumph-of-cost-benefit-analysis

Thompson KM, Rabouw RF, Cooke RM (2001) The Risk of Groundling Fatalities from Unintentional Airline Crashes. Risk Analysis 21, 1025-37. 
US EPA (US Environmental Protection Agency) (2006) EPA's Action Development Process: Guide to Considering Children's Health When Developing EPA Actions: Implementing Executive Order 13045 and EPA's Policy on Evaluating Health Risks to Children. [Last accessed 15 July 2016.] Available from URL: https:/www.epa.gov/sites/production/files/2014-05/documents/ epa_adp_guide_childrenhealth.pdf

US EPA (US Environmental Protection Agency) (2010) 40 CFR Parts 50, 53, and 58: Primary National Ambient Air Quality Standard for Sufur Dioxide; Final Rule. Federal Register 75 (119), 35520-35602. [Last accessed 15 July 2016.] Available from URL: http:// www3.epa.gov/ttn/naaqs/standards/so2/fr/20100622.pdf

US EPA (US Environmental Protection Agency) (2011) Exposure Factors Handbook. EPA/600/R-090/052 F. [Last accessed 15 July 2016.] Available from URL: https:/www.epa.gov/expobox/exposure-factors-handbook-2011-edition

US EPA (US Environmental Protection Agency) (2014) Plan EJ 2014: Legal Tools. Office of General Council, US EPA, Washington DC. [Last accessed 15 July 2016.] Available from URL: https://www.epa.gov/sites/production/files/2015-02/documents/ej-legal-tools.pdf

US EPA (US Environmental Protection Agency) (2016) Regulatory Flexibility for Small Entities [Last accessed 15 July 2016.] Available from URL: http://www.epa.gov/rfa/overview.html

Vesell ES (1985) Implications for Risk Assessment of Host Factors Causing Large Pharmacokinetic Variations. Toxicology and Industrial Health 1 (4), 135-152.

Viscusi WK (2007) The Flawed Hedonic Damages Measure of Compensation for Wrongful Death and Personal Injury. Journal of Forensic Economics 20 (2), 113-135.

Viscusi WK (2012) What's to know? Puzzles in the Literature on the Value of Statistical Life. Journal of Economic Surveys 26, $763-768$. Wagner WE (2000) The Triumph of Technology-based Standards. University of Illinois Law Review 2000 (1), $83-113$.

West WF (2015) The Administrative Presidency as Reactive Oversight: Implications for Positive and Normative Theory. Public Administration Review 75, 523-533.

Wildavsky A (1979) The Politics of the Budgetary Process. Little, Brown, Boston, MA.

Williams R, Broughel J (2015) Principles for Analyzing Distribution in Regulatory Impact Analysis. Mercatus Center, George Mason University, Arlington, VA.

Woodruff TJ, Zeise L, Axelrad DA, Guyton KZ, Janssen S, Miller M et al. (2008) Meeting Report: Moving Upstream-Evaluating Adverse Upstream End Points for Improved Risk Assessment and Decision-making. Environmental Health Perspectives 116, 1568-1575.

\section{Appendix \\ Cases Cited}

Industrial Union Department v. American Petroleum Institute (The Benzene Case), 448 U.S. 607 (1980)

\section{Laws Cited}

Clean Air Act of 1970, 42 U.S.C. $\$ 7401$ et seq. (1970)

Consumer Product Safety Act of 1972 as amended, 15 U.S.C. \$2056 (1970)

Dodd-Frank Wall Street Reform and Consumer Protection Act, Pub.L. 111-203, July 21, 2010

Food Quality Protection Act of 1996, Public Law 104-170, August 3, 1996.

Occupational Safety and Health Act of 1970, 29 U.S.C. 15, Sec. 651 et. seq. (1970).

Regulatory Flexibility Act (RFA) of 1980, 5 U.S.C. 601-612.

Small Business Regulatory Enforcement Fairness Act (SBREFA) of 1996, 5 U.S.C. \$201 et. seq.

The Frank R. Lautenberg Chemical Safety for the 21st Century Act, 15 U.S.C \$2601 et seq. (2016)

Toxic Substances Control Act of 1976 as amended, 15 U.S.C. $\$ 2601$ et seq. (1976) 